\title{
The Lingua Franca Core (LFC) and Its Impact on Pronunciation Teaching Practice in Indonesia
}

\author{
Jaelani \\ Univerisitas Islam Negeri Mataram \\ allanj@uinmataram.ac.id
}

Received: $22^{\text {nd }}$ October 2021| Revised: $27^{\text {th }}$ October 2021| Accepted: $20^{\text {th }}$ November 2021

Email Correspondence: allanj@uinmataram.ac.id

\begin{abstract}
English pronunciation is a crucial part of communication however, it can be overwhelmingly challenging for non-native speaker students. Phonologically, it is because of its inconsistent orthography and idiosyncratic phonetics; it is also idiosyncratic or distinctive and not universal. To overcome such problems, Jenkins proposes a Lingua Franca Core (LFC). Despite its potential benefits, the LFC is practically and administratively challenging to be implemented in pronunciation learning practice in Indonesia. Thus, aiming to find issues regarding LFC in pronunciation teaching practices in Indonesia, data generated from ten Indonesian educational practitioners with diverse language backgrounds are qualitatively analyzed in this study. This study indicates that, practically, the replacement of dental fricatives $/ \theta /$ and $/ ð /$ and its replacements with labiodental fricatives $/ \mathrm{f} /$ and $/ \mathrm{v} /$ is a failed suggestion and might lead to the fossilization of these sounds. Also, the LFC in the sentence level of utterance might not be as significant as in the word level. Administratively, LFC is challenging because of teachers' limited knowledge, training, and sources regarding assessing students' English pronunciation skills, teachers' and students' attitudes toward certain English accents, and the fact that pronunciation is not explicitly being taught in English class in Indonesia.
\end{abstract}

Keywords: LFC, pronunciation, phonetics, practicality, administrative

\section{INTRODUCTION}

English as a lingua franca gains massive attention worldwide recently. In 2018, it is recorded that the non-native speakers outnumbered the native speaker by a ratio of about three to one (Szmigiera, 2021). The significance of English as a lingua franca leads to substantial changes in language curriculum design in Indonesia, and one of them is making English one of four compulsory subjects to be tested in the national exam in Indonesia. Despite its crucial role in global communication, the focus of English teaching in Indonesia is seemly only the grammar of such a language and have not been touched teaching the correct pronunciation as an urgent issue (Musthafa, 2015). English pronunciation is a crucial part of communication, and the mistakes in its pronunciation might mislead the non-native speakers (Wells, 2005). Thus, this paper aims to discuss the Pronunciation Teaching Practice in Indonesia. How the

Online at https://journal.universitasbumigora.ac.id/index.php/humanitatis/

DOI : https://doi.org/10.30812/humanitatis.v8i1.1522 
Lingua Franca Core (FLC) is challenging in language education in Indonesia will be discussed in this paper. Indonesia is chosen for its diversity in cultures and native languages that potentially significantly influence English learning; Indonesia also consists of over 300 native languages exist in this country and every language has its own dialect and system of sounds that might influence Indonesians' English pronunciation (Sandjaja, 2018).

A lingua franca is a term used referring to a language adopted as a medium to communicate between interlocutors with different native languages (Samarin, 1987). Historically, it occurred because of a variety of social phenomena such as the needs of its speakers to spread their culture, religion, and territory. In the modern-day, easy access to the global community leads to the significant need for a lingua franca to share knowledge as well as for economic purposes. Although countless examples of lingua franca can be discovered in all continents, with around 1.5 billion people speaking English, and over 1.1 billion of them are speaking other languages as their native language, English can be considered as a global lingua franca (Crystal, 2003; Northrup, 2013; Szmigiera, 2021). It means that regardless of its number three position globally, since it is used dominantly by the most native speaker and non-native speakers, English is taken place as the global lingua franca.

English phonology can be overwhelmingly challenging for non-native speaker students. Phonologically, it is because of its inconsistent orthography and idiosyncratic phonetics. Wells (2005) argues that orthography in English is unpredictable and irregular because the spelling and the pronunciation might be different. When an individual is given a pronounced word to spell, there is no guarantee that they will correctly spell it, or when a non-native speaker is given spelled word, there is a possibility for them to pronounce or utter it wrong. Vowel 'a', for instance, might be pronounced differently in Australian English; in 'Ask', it pronounces /v:sk/, but in 'Ape', it sounds/ ærp/. It can also be pronounced /smo:1/ in 'Small' and /eni:/ in 'Any' (see also Cox \& Fletcher, 2017). Such a case might significantly affect speakers with more persistent orthography and idiosyncratic phonetic languages such as Indonesians and Germanies.

Another issue in English phonetics is it is also idiosyncratic or distinctive and not universal. It means that some characteristics of English can hardly be found in other languages. It has confusing unique characteristics that might be problematic for both subject teachers and students (Wells, 2005). English has a complicated vowel and consonant system; the example of a non-widespread vowel system can be found in the previous paragraph. An example of a uniquely complex consonant system in English is the dental fricatives $/ \theta /$ and $/ \delta /$. In other languages, such as Bahasa Indonesia, both voiced dental

Online at https://journal.universitasbumigora.ac.id/index.php/humanitatis/

DOI $\quad$ : https://doi.org/10.30812/humanitatis.v8i1.1522 
fricatives $/ \theta$ / and voiceless dental fricatives /ð/ do not exist. Thus, it might be challenging for Indonesian to native-likely pronounce words such as 'They,' 'The,' or 'Founded.'

To overcome problems regarding the previously mentioned English phonology, Jenkins (2002) proposes a Lingua Franca Core (LFC) which is any features of English pronunciation (Consonants, Vowels, Prosody) that are essential for international intelligibility. She argues that all consonants, but dental fricatives $/ \theta /$ and $/ ð /$, should be included, and the final $/ \mathrm{r} /$ in words, such as "here", "hair" and so forth, should be maintained as in American English (in British English, the final / $\mathrm{r}$ / is omitted). Besides, a medial /t/ should be voiceless as a British English speaker does, and phonemic distinctions need to be maintained.Furthermore, related to consonants, when it comes to words with initial voiceless stops /p, t, $\mathrm{k} /$, the word should be aspirated (for example, 'Pin' will pronounce $/ \mathrm{p}^{\mathrm{h}} \mathrm{In} /$ ). Besides, consonants in the word with initial clusters, such as 'Promise' and 'String', should not be omitted; it is possible to omit medial and final clusters based on English-native speaker rules (see also Dauer, 2005; Jenkins, 2002).

Related to vowels, there should be a contrast in the vowel length (Short vs. Long). 'Heed' and 'Hid', for instance, to distinguish their pronunciations, these two words should have a clear length vowel difference; these two words pronounce /hi:d/ and /hId/ respectively. Moreover, a short vowel should precede voiceless consonants whereas a longer vowel comes before voiced consonants. Besides, nuclear stress should be placed on the right syllable, and it should be produced in the appropriate and precise length stress. Based on the previous explanation, LFC seems to promote a universal and more consistent language norm in English as a Lingua Franca. Despite its cruciality to provide or propose a stable universal consonant system that might be used in a variety of English by both native speakers and Nonnative speakers, some detailed features in LFC promoted by Jenkins $(2000,2002)$ might be practically and administratively challenging to be implemented in pronunciation learning practice. Thus, this study aims to find issues regarding LFC in pronunciation teaching practices in Indonesia.

\section{RESEARCH METHOD}

To provide significant valid and relevant data, the author conducted a qualitative approach study based on experience-based descriptive data collected. Data were collected from ten Indonesian educational practitioners with more than five years of working experience in English teaching; the participants are multilingual with different native language backgrounds from five different areas in Indonesia namely Ambon, Kupang, Lombok, Surakarta, and Yogyakarta. To facilitate the study, the author utilizes online platforms such as Zoom Meeting and WhatsApp Messenger to conduct interviews.

Online at https://journal.universitasbumigora.ac.id/index.php/humanitatis/

DOI $\quad$ : https://doi.org/10.30812/humanitatis.v8i1.1522 
In its process, both phonemic and phonetic transcriptions will be used in this paper depending on the needs of the author.

\section{FINDINGS AND DISCUSSION}

The descriptions and analyses of the findings are directed to answer the research questions: What are the issues of LFC regarding English Pronunciation Teaching Practice in Indonesia? The data indicate that LFC promoted by Jenkins has practicality and administrative-related issues in its practice in Indonesia, and such issues will be discussed in the following sections.

\subsection{English Phonology in Indonesian Education}

Unlike English, Indonesian pronounce the words as the letters are written and when the letters are moved, the way to pronounce them will also change accordingly. The vowel ' $U$ ' in Bahasa Indonesia, for instance, word $\underline{S a p u}$, which means 'broom', will be pronounced /'sa:pu/, whereas Usap, which means 'wipe' is pronounced /' $\boldsymbol{y}_{1}$ sap/. Also, when the letterforms different word formation such as $\underline{\text { Urat }}$, which means 'muscle', it will still be pronounced /' $u_{1}$.rat/. Moreover, when the word had two syllables and is mentioned in a single word (not in a sentence), the primary stress will be on the first syllable whereas the secondary stress will be on the second syllable. Nevertheless, when the word contains three or more syllables, the primary stress will be the first syllable, and the secondary stress will be the third syllable. Thus, Bahasa Indonesia is more predictable than English.

\subsection{Language Franca Core in Perspective of Indonesia}

As previously discussed, LFC, despite its potential uses, is still problematic in some specific features in some countries. As previously mentioned, this section is divided into practicality and administrative issue of LFC in Indonesia

\subsubsection{Practicality Issues of LFC in Indonesia}

Jenkins (2000) argues that dental fricatives $/ \theta /$ and / $/$ might be omitted in LFC and replaced with /f/ and /v/. Such particular omission raises a question about the maintenance of postalveolar fricative /g/ and $/ 3 /$ which is, in the Indonesian Language (Bahasa Indonesia), also difficult to pronounce. Also, in its practice, omitting only dental fricative $/ \theta /$ and /ð/ will not significantly affect both teachers' and students' workload since they still need to master how to produce other consonants and vowels that might do not exist in their local tongues. Such a finding is aligning with Dauer (2005) that also adds that /v/ sound is problematic for many English pronunciation learners thus, instead of replacing dental fricatives / $/$ / and /ð/ with labiodental fricative /f/ and /v/, it will be easier for the students if they are replaced with alveolar plosive /t/ and /d/.

Online at https://journal.universitasbumigora.ac.id/index.php/humanitatis/

DOI $\quad$ : https://doi.org/10.30812/humanitatis.v8i1.1522 
Moreover, the omission of dental fricatives $/ \theta /$ and $/ ð /$ and its replacements with labiodental fricatives /f/ and /v/ will not necessarily positively affect both the learning workload and the challenging in English pronunciation learning practice. Also, in this case, it is not the dental fricatives that the problem, it is its replacement. Although initially they pronounced 'Thin' as /tin/ and 'These' as /di:z/, all participants admitted that in English pronunciation learning practices, they are easily turned into /ðrn/ and $/ \theta \mathrm{i} z /$. It means Indonesian students might overcome the absence of dental fricatives $/ \theta /$ and $/ ð /$ consonants in Bahasa Indonesia. The problem might be the labiodental fricatives /f/ and /v/ as the replacement because /v/ sound does not exist in Indonesia and forcing /f/ sound as a replacement cause the fossilization of these sounds. One of the participants, for example, pronounced /ae 'wontəd to fak maj bok/ to 'I wanted to pack my book'.

Another challenging practicality aspect in English pronunciation learning practice in Indonesia is the vowel length. The limited examples provided by Jenkins $(2000,2002)$ do not give a clear explanation about cases that occurred beyond that two pairs of vowel lengths examples (/u/ vs. / $/ /$ and $/ \mathrm{I} / \mathrm{vs}$. $/ \mathrm{i} /$ as in 'Cooed' vs. 'Could' and 'Leave' vs. 'Live'). Moreover, including / $/$ in LFC is also questioned since it occurs in an only limited number of words (although they are frequently used such as at 'good' and 'should'). The length of vowel distinction in LFC is defined regarding an analysis of the non-rhotic. British English vowel system but pronouncing final / $\mathrm{r}$ / indicates that LFC is not based on the British English phonetic system. Thus, it is confusing to define which vowel contrasts are included in the LFC system.

The limited examples in consonant omissions given by Jenkins $(2000,2002)$ are also problematic. In Bahasa Indonesia, no consonant or syllable is being omitted; all written consonant is uttered. Taking an example provided by Wells (2005), when native speaker pronounces 'Climbing' as /'klaimin/ or /'klaimın/, Bahasa Indonesia does not recognize a silent sound. Thus, it will be pronounced /'klaimbin/. However, for some specific words, suchas 'Island', the participants omit the /s/ sound. It is because such a word is considered as a member of 'the most frequently used' words in Indonesia; Indonesia is an archipelago. It means that the /s/ sound in 'Island' is omitted because of the participants' background knowledge in the pronunciation of such a word.

Out of LFC system provided by Jenkins (2000) (because it is not explicitly discussed), both phonetic and phonemic system symbols might also be problematic for the learners; the members of the 'inner circle' have a slightly different phonetic and phonemic system symbols. Australian English, for instance, use symbols $/ \mathrm{I} /$ and $/ \mathfrak{t} /$ that can hardly be found in other types of English such as American English, British English, and so forth. To master these symbols and to implement their sounds in English

Online at https://journal.universitasbumigora.ac.id/index.php/humanitatis/

DOI $\quad$ : https://doi.org/10.30812/humanitatis.v8i1.1522 
pronunciation teaching practice in Indonesia, it is compulsory for the teachers to have excellent phonetic training which many teachers lack.

Another practical issue in LFC implemented in Indonesia is its intonation and stress norms. According to the participants, it is always easy to follow the suggestion promoted by Jenkins (2000, 2002) at the word level but harder to keep on track at the sentence level. In Indonesia, when the word had twosyllables and is mentioned in a single word (not in a sentence), the primary stress will be on the first syllable whereas the secondary stress will be on the second syllable. Nevertheless, when the word contains three or more syllables, the primary stress will be the first syllable, and the secondary stress will be the third syllable. It also affects the participants' pronunciation at the sentence level. They tend to stress every first syllable of words in a sentence.

The last feature might be challenging in pronunciation learning practicein Indonesia is the aspiration of word-initial voiceless stops $/ \mathrm{p} /, / \mathrm{t} /$, and $/ \mathrm{k} /$. Such a simple feature is considered challenging for the majority of participants butthe participant with Javanese language background. They tend to put aspiration as frequently as possible because, in their native language, such practice iscommon. They called it jawa medok' which means 'totally Javanese'. It means, even for the non-native speakers that share the same national language,their native language also influences their execution of LFC. In short, it is not possible for every speaker of English to be intelligible to other speakers of English (see Bayyurt, 2018).

\subsubsection{Administrative Issues of LFC in Indonesia}

Teachers as one of the stakeholders have a significant role in pronunciation learning practice; they are the role models whom the students can imitate (Celce-Murcia et al., 1996). However, the majority number of teachers is indicated to have insufficient formal preparation or training to teach pronunciation. All the participants admitted that they have not included or joined any formal training to teach pronunciation as a part of their professional development. Moreover, such an issue is not aligning with cases for not only English non-native speaker teachers but also the English native speaker teachers. In Canada for instance, approximately $67 \%$ of its English Second Language (ESL) teachers have never been involved in any pronunciation-related training. Teachers' unwillingness to teach such important language subskill, a limited opportunity or insufficient information regarding pronunciation-related training, and unsupportive superiors are the reasons for such an issue; this aligns with a study conducted by MacDonald (2002).

Another administrative problem in pronunciation teaching practice in Indonesia is the lack of LFC-related resources. Deterding (2011) argues that there is a severely insufficient number of readings and multimedia, such as sounds and videos, resources discussing universal norms in English

Online at https://journal.universitasbumigora.ac.id/index.php/humanitatis/

DOI : https://doi.org/10.30812/humanitatis.v8i1.1522 
pronunciations. All participants agree that accessing textbooks and multimedia sources, especially audio sources is crucial in pronunciation teaching practice. Audio sources used in language class assist learners to become familiar with features in LFC; they also raise awareness of issues surrounding accent, intelligibility, and pronunciation goals (Walker, 2010). It is worsened by the fact that the topic discussion designed in curricula also tends to ignore the topic of English speech sounds. It means the current language curriculum design, which focuses more on the grammar function of English, failed to facilitate students in English pronunciation in Indonesia.

Furthermore, since English system sound is not one of the focusing aspects in language curriculum design in Indonesia, and English curriculum design in Indonesia takes more attention in mastering English grammar than in pronunciation, an answer for a question such as whether or not Indonesian students need to learn English pronunciation possibly can be answered by answering some crucial questions promoted by Wells (2005): What to teach and Aims to educate. Since speaking is not a part of the national exam and language curriculum design, it will not be necessary for students to learn the correct pronunciation or LFC. Besides, as previously mentioned that the participants admitted that there is no single training conducted to help the teacher to teach pronunciation or even to promote pronunciation in learning practice itself.

An attempt to include the pronunciation aspect in language learning design is also problematic. Since there are no fixed norms in LFC, the evaluation of students' improvement in pronunciation seems to be extremely hard to be conducted. Teachers will not be able to assess students' performance without knowing the fixed rules to follow. Evaluating students' performance in pronunciation is important to determine whether or not they are producing a correct sound referring to the correct action or noun, so any decision related to their knowledge can be made (Roever \& McNamara, 2006). Teachers' and students' attitudes toward LFC will also determine its implementation in pronunciation learning practice. The participants admitted that in their English teaching practice, producing sounds exactly as English native speakers do not consider a crucial or significant part (unnecessary); this finding aligns with a study conducted by Deterding (2011). Thus, LFC is hard to successfully be implemented if both teachers and students have no intention to apply it.

Furthermore, as might be occurred in other countries, there is a limited number of resources about pronunciation and LFC in Indonesia. With no training and limited access to any kinds of literature discussing English pronunciation, the teacher's knowledge about how to asset students' English pronunciation skills is limited. Thus, they tend to avoid deeply teaching English pronunciation. It leads to the unsuccessful implementation of LFC in English pronunciation teaching practice in Indonesia.

Online at https://journal.universitasbumigora.ac.id/index.php/humanitatis/

DOI $\quad$ : https://doi.org/10.30812/humanitatis.v8i1.1522 
Moreover, teachers' and students' attitude towards the type of English also might cause theirignorance to LFC. The participants state that it is common knowledge in Indonesia that the majority of Indonesians consider British English as original English and used by noble. Thus, they tend to give more attention and follow the British English pronunciation rule and slightly ignore the others.

\section{CONCLUSION}

The massive number of English speakers lead such language used as a linguafranca. Due to its features, English phonology can be overwhelmingly challenging fornon-native speaker students. However, Jenkins promotes English as an LFC to make English pronunciation more universal and consistent in rules. However, some detailed features provided by Jenkins are debated by some linguists. In the case of Indonesia, LFC might be problematic because of its practicality and administrative issues. Practically, the replacement of dental fricatives $/ \theta /$ and $/ ð /$ and its replacements with labiodental fricatives /f/ and $/ \mathrm{v} /$ might be a failed suggestion in Indonesia because /v/ sound does not exist, and forcing /f/ sound might lead to the fossilization of this sounds. The first language influence in stressing or intonation might also determine the success of LFC in Indonesia. Indonesians might successfully follow the LFC in the word level of utterance but not in the sentence level. Administratively, pronunciation is not explicitly being taught in English class. It is because speaking is not a part of national exam and language curriculum design; there is no training and sources such as textbooks and multimedia sources can be used as references in teaching English pronunciation. Thus, the teachers' knowledge about how to asset students' English pronunciation skill is limit and lead them to avoid teaching pronunciation. Moreover, teachers' and students' attitudes that consider British English as the 'real' and noble language might cause them to ignore LFC. However, the author claims in this paper need more deeply study. An attempt to study possible suggestions or solutions to overcome issues in Jerkins' LFC need also be conducted. Thus, in the future, better features in LFC that might be implemented better in the broader scope of English education can be provided.

\section{REFERENCES}

Bayyurt, Y. (2018). Issues of intelligibility in world Englishes and EIL contexts. World Englishes, 37(3), $407-415$.

Celce-Murcia, M., Brinton, D. M., \& Goodwin, J. M. (1996). Teaching pronunciation: A reference for teachers of English to speakers of other languages. Cambridge University Press.

Cox, F., \& Fletcher, J. (2017). Australian English pronunciation and transcription. Cambridge University

Online at https://journal.universitasbumigora.ac.id/index.php/humanitatis/

DOI $\quad$ : https://doi.org/10.30812/humanitatis.v8i1.1522 
Press.

Crystal, D. (2003). English as a global language. Ernst Klett Sprachen.

Dauer, R. M. (2005). The lingua franca core: A new model for pronunciation instruction? Tesol Quarterly, 39(3), 543-550.

Deterding, D. H. (2011). English Language Teaching and the Lingua Franca Core in East Asia. 92-95.

Jenkins, J. (2000). The phonology of English as an international language. Oxford university press.

Jenkins, J. (2002). A sociolinguistically based, empirically researched pronunciation syllabus for English as an international language. Applied Linguistics, 23(1), 83-103.

MacDonald, S. (2002). Pronunciation-views and practices of reluctant teachers.

Musthafa, B. (2015). Communicative language teaching in Indonesia: Issues of theoretical assumptions and challenges in the classroom practice. Teflin Journal, 12(2), 184-193.

Northrup, D. (2013). How English became the global language. Springer.

Roever, C., \& McNamara, T. (2006). Language testing: The social dimension. International Journal of Applied Linguistics, 16(2), 242-258.

Samarin, W. J. (1987). Lingua franca. Walter de Gruyter.

Sandjaja, D. P. (2018). Asian Languages \& Literature: Indonesia. https://asian.washington.edu/fields/indonesian

Szmigiera, M. (2021). The most spoken languages worldwide in 2021. https://www.statista.com/statistics/266808/the-most-spoken-languages-worldwide/

Walker, R. (2010). Teaching the pronunciation of English as a lingua franca (Vol. 345). Oxford University Press Oxford.

Wells, J. C. (2005). Goals in teaching English pronunciation. English Pronunciation Models: A Changing Scene, 101-110.

Online at https://journal.universitasbumigora.ac.id/index.php/humanitatis/

DOI : https://doi.org/10.30812/humanitatis.v8i1.1522 
Online at https://journal.universitasbumigora.ac.id/index.php/humanitatis/

DOI : https://doi.org/10.30812/humanitatis.v8i1.1522 